\title{
Primary cardiac hemangioendothelioma of the right ventricle
}

Xiaoyan Chen ${ }^{1}$, Jianxiu Fang ${ }^{1}$, Qingmei Yang $^{1}$, and Haifeng Guo ${ }^{1}$

${ }^{1}$ Affiliation not available

November 24, 2020

\begin{abstract}
Primary cardiac hemangioendothelioma is a very rare low-grade malignancy. We present a case of a 41-year-old female patient with a huge primary cardiac hemangioendothelioma that arose from the right ventricle was recurred after being removed, and the diagnostic images given by echocardiography.
\end{abstract}

\section{Hosted file}

manuscript1000.pdf available at https://authorea.com/users/369642/articles/494918-primarycardiac-hemangioendothelioma-of-the-right-ventricle 

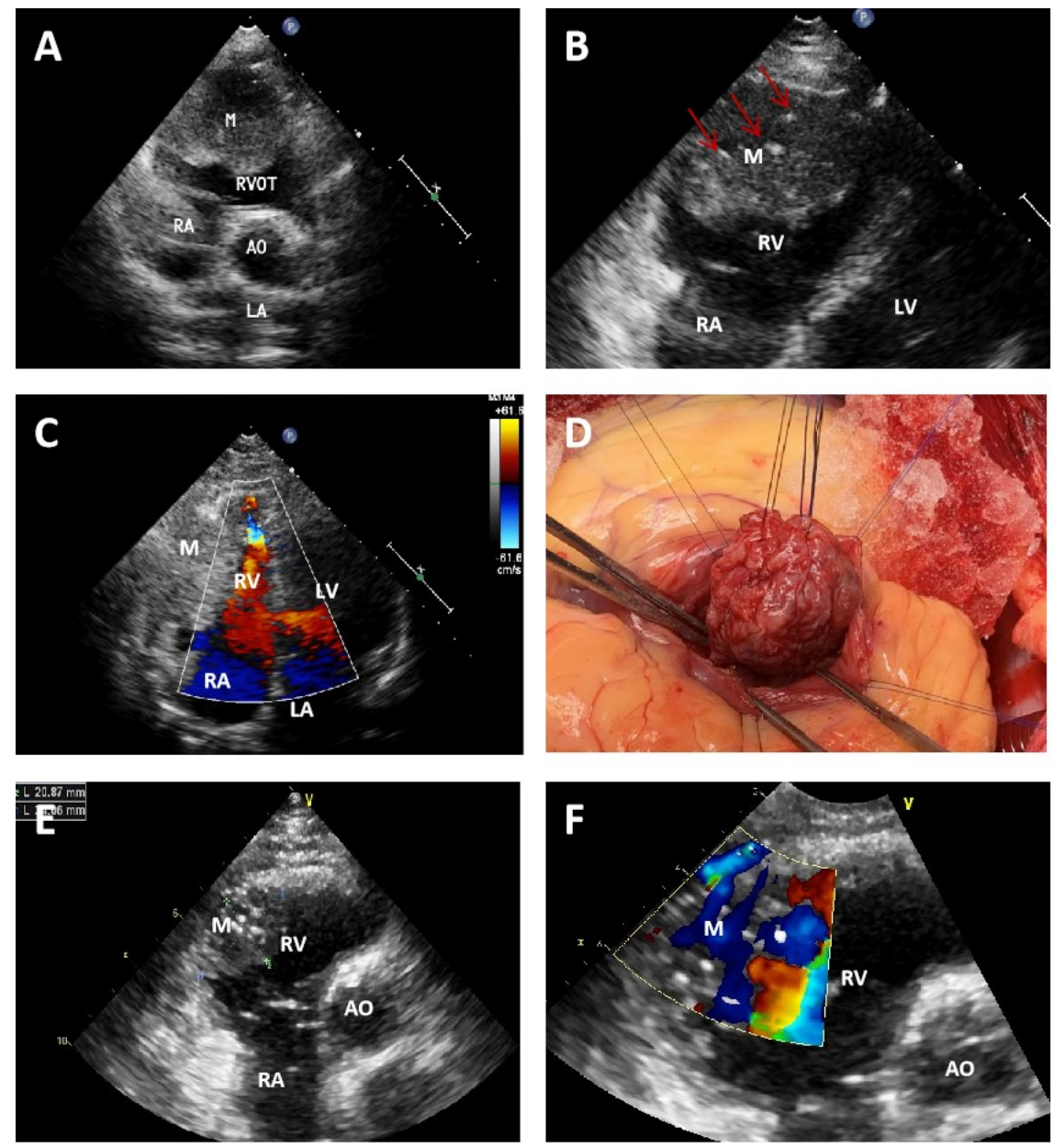